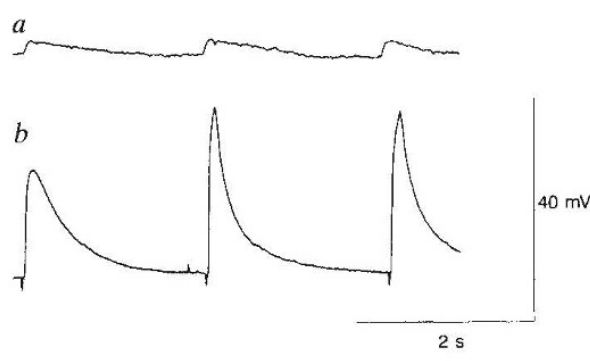

Excitatory junction potentials (EJPS) in the second-order ileal mesenteric arteries of a four-month-old hypertensive rat $(b)$ compared to a four-month-old normotensive rat (a). The records show the largest EJPs recorded to supramaximal perivascular stimulation in the arteries studied (seven hypertensive and five normal rats; age range three to five months; stimulating pulse $100 \mathrm{~V}, 1 \mathrm{~ms})$. The first EJP had a time course similar to that observed for EJPs in the other arteries from the hypertensives. However, the second and third EJPs in the train of stimuli had faster time courses. These two EJPs were facilitated becoming so large as to activate peaked, presumably voltage-dependent responses. The mean peak amplitude of the first EJP recorded for each artery from the same seven hypertensive and five normal rats was $14.4 \pm 2.8$ and $2.3 \pm 0.7 \mathrm{mV}$, respectively. The vessels were studied in vitro in a standard physiological fluid at $35^{\circ} \mathrm{C}$ with recordings made using intracellular glass microelectrodes filled with $0.5 \mathrm{M} \mathrm{KCl}$

second messenger ${ }^{3}$. A second pathway for constriction is through activation of excitatory junction potentials which can summate to activate voltage-dependent calcium channels. Studies on the WistarKyoto rat, the genetic control for the hypertensive rat, have shown that the resistance vessels have small excitatory junction potentials and undergo neurally mediated constriction predominantly through activation of $\alpha$-adrenoreceptors ${ }^{4}$.

In hypertension, structural changes occur in the walls of the resistance vessels (see refs 2, 5 for reviews). There is a considerable proliferation of smooth muscle cells, leading to a thicker wall through increased numbers of these gap junction-coupled cells. The sympathetic innervation is also increased. But, as for the resistance arteries from control animals with normal blood pressure, this innervation remains in the adventitia, forming synapses only with the outer layer of smooth muscle. These hypertensionassociated changes make traditional noradrenergic transmission increasingly ineffectual to the inner muscle. This arises through both the inner smooth muscle being further removed from the neural source of noradrenaline and there being

1. Lee, R.M., Triggle, C.R., Cheung, D.W. \& Coughlin, M.D Hypertension 10, 328-338 (1987)

2. Head, R.J. Blood Vessels 26, 1-20 (1989)

3. Hashimoto, T., Hirata, M., Itoh, T., Kanmura, Y. \& Kuriyama, H. J. Physiol., Lond. 370, 605-618 (1986).

4. Angus, J.A., Broughton, A. \& Mulvany, M.J. J. Physiol.

Lond. 403, 495-510 (1988)

5. Folkow, B. Physiol. Rev. 68, 347-504 (1982) greater re-uptake of noradrenaline by the nerves.

The finding of markedly enhanced excitatory junction potentials in the hypertensive rat compared with the control (see figure) is therefore of considerable significance as it underlies a shift from chemical to electrical signalling. The enhanced sympathetic co-transmission would be expected to facilitate recruitment of all muscle layers, electrical signalling overcoming the limitations of the chemically mediated $\alpha$-adrenergic mechanisms. Constriction should there-

\section{El Niño prediction}

SIR-In November 1989 we made a forecast, based on analysis of changes in the length of day, that an El Niño event has been developing since the previous one in 1986-87 and that it would reach a peak intensity in the second half of 1990 . We also predict that the sea-surface-temperature anomaly induced by the new El Niño event will be stronger than that in 1986-87.

Since the El Niño event in 1982-83, which was characterized by the anomalous warming up of the sea surface water in the equatorial area of the eastern Pacific, there has been significant progress in elucidating the relationship between the variation of the rate of the Earth's rotation and $\mathrm{E} I \mathrm{Niño}$ events ${ }^{1-7}$. It has been suggested ${ }^{5,6}$ that $\mathrm{El}$ Niños could be predicted by changes in day length.

The variation of the Earth's rotation is influenced by many astronomical and geophysical factors $^{8.9}$. Applying the techniques of multi-stage filter (MSF) and leap-step autoregression (LSAR) that we have described $^{10.11}$ could increase the reliability of predictions based on changes in day length.

Using astronomical data collected between January 1962 and October 1989 (refs 12-14) we obtained a series of changes in day length over a 30-day interval. According to the frequency band scales $(2-7 \mathrm{yr})$ of seven El Niño events since 1962, the series of day-length changes can be processed with the band-pass filtering using MSF and LSAR (top trace in figure) and the monthly departures of the sea-surface temperature (SST) in the equatorial eastern Pacific from January 1962 to February 1988 (bottom trace of figure). The figure clearly shows that the interannual rate of the Earth's rotation decelerates when the sea water warms up and accelerates when the water cools down. Thus, every El Niño event usually occurs after the turn of the interannual rate of the Earth's rotation from accleration to decelaration. We also find that the amplitudes fore exhibit an increased dependence on voltage-dependent calcium entry compared with the predominantly $\alpha$-adrenergic mechanism of the normotensive control ${ }^{4}$. This might explain the success of calcium antagonists in combating hypertension in the hypertensive rat and could be true also in man.

DiRK F. VAN HELDEN SONJA WOOLRIDGE

The Neuroscience Group,

Faculty of Medicine,

University of Newcastle,

New South Wales 2308, Australia

of the interannual change in day length are correlated with the strength of El Niño events. Since 1962, the two strongest El Niño events occurred in 1972 and in 1982-83, and in both the amplitudes of interannual variation in day-length change were larger. Thus the epoch and magnitude of El Niños can be predicted. Our analyses suggest that the late 1990
El Niño event will be stronger than that in 1986-87, and that it might last until 1991.

\section{W. ZHENG G. X. SONG S. F. LUO}

Shanghai Obsenvatory

Chinese Academy of Sciences, Shanghai 200030

Peoples Republic of China

1. Carter, W. E. et al. Science 224, 957-961 (1984)

2. Rosen, R.D. et al. Science 225, 411-414 (1984).

3. Chao, B.F. Geophys, res. Lett. 11, 541-544 (1984)

4. Ren, Z.Q. \& Zhang, S. G. Kexue Tongbao 6, 444-447 (1985).

5. Eubanks, T. M. et al. Earth Rotation: Solved and Unsolved Problems 163-187 (Reidel, Dordrecht, 1986).

6. Zheng, D. W., Luo, S. F. \& Song, G. X. Science in China (Series B) 32, 729-736 (1989)

7. Song, G. X., Zheng, D.W. \& Luo, S. F. Acta astr. Sinica 30. 310-314 (1989).

8. Lambeck. K. The Earth's Variable Rotation (Cambridge University Press, New York, 1980)

9. Luo, S. F et al Acta astr. Sinica 15, 79-84 (1974).

10. Zheng, D. W. \& Dong, D. N. Acta astr. Sinica 27, 368-375 (1986)

11. Zheng, D. W. Progr. Astr. 7, 118-124 (1989).

12. Li, Z. X. in Annual Report for 1984, D31-D36 (Bureau International de l'Heure, 1985).

3. BIH Annual Report for 1982-1987 (Observatoire de Paris, 1983-88).

4. IERS Annual Report for 1988 and Bulletin B for 1989 (Observatiore de Paris, 1989). 